\title{
Diet May Moderate the Relationship Between Arterial Stiffness and Cognitive Performance in Older Adults
}

\author{
Sarah Gauci ${ }^{\mathrm{a}, \mathrm{b}, *}$, Lauren M. Young ${ }^{\mathrm{a}, \mathrm{c}}$, David J. White ${ }^{\mathrm{a}}$, Jeffery M. Reddan ${ }^{\mathrm{a}}$, \\ Annie-Claude Lassemillante ${ }^{\mathrm{d}}$, Denny Meyer ${ }^{\mathrm{e}}$, Andrew Pipingas ${ }^{\mathrm{a}}$ and Andrew Scholey ${ }^{\mathrm{a}, \mathrm{f}}$ \\ ${ }^{a}$ Centre for Human Psychopharmacology, Swinburne University, Melbourne, VIC, Australia \\ ${ }^{\mathrm{b}}$ Heart and Mind Research, IMPACT, Institute for Innovation in Physical and Mental Health and Clinical \\ Translation, School of Medicine, Deakin University, Geelong, Australia \\ ${ }^{\mathrm{c}}$ Food and Mood Centre, IMPACT, Institute for Innovation in Physical and Mental Health and Clinical \\ Translation, School of Medicine, Deakin University, Geelong, Australia \\ ${ }^{\mathrm{d}}$ Department of Nursing and Allied Health, Faculty of Health, Arts and Design, Swinburne University, Melbourne, \\ VIC, Australia \\ ${ }^{\mathrm{e}}$ Department of Health Science and Biostatistics, Centre for Mental Health, Swinburne University, Melbourne, \\ VIC, Australia \\ ${ }^{\mathrm{f}}$ Nutrition Dietetics and Food, School of Clinical Sciences, Monash University, Melbourne, VIC, Australia
}

Accepted 25 October 2021

Pre-press 30 November 2021

\begin{abstract}
.
Background: Cognitive decline is influenced by various factors including diet, cardiovascular disease, and glucose control. However, the combined effect of these risk factors on cognitive performance is yet to be fully understood.

Objective: The current study aimed to explore the inter-relationship between these risk factors and cognitive performance in older adults at risk of future cognitive decline.

Methods: The sample comprised 163 (Age: $M=65.23$ years, $S D=6.50$ ) participants. Food Frequency Questionnaire data was used to score diet quality and adherence to the Western Style Diet (WSD) and Prudent Style Diet (PSD). Glucose control was gauged by serum levels of glycated hemoglobin (HbAlc) and arterial stiffness was measured using carotid to femoral pulse wave velocity. Cognitive performance was assessed using two subtests of the Swinburne University Computerized Cognitive Assessment Battery (SUCCAB) and Rey's Verbal Learning Test (RVLT).

Results: Diet quality, adherence to the WSD or PSD, and glucose control were not significantly related to cognitive outcomes. However, a significant negative association was found between arterial stiffness and the spatial working memory subtest of SUCCAB $(\beta=-0.21, p<0.05)$. Arterial stiffness also significantly interacted with the PSD to impact total recall ( $F$ change $(1,134)=5.37, p<0.05)$ and the composite score of RVLT $(F$ change $(1,134)=4.03, p<0.05)$.

Conclusion: In this sample of older adults at risk of cognitive decline, diet alone was not found to predict cognitive performance; however, it was found to moderate the relationship between arterial stiffness and cognition.
\end{abstract}

Keywords: Aging, arterial stiffness, cognition, diet, dietary patterns, glucose control, working memory

${ }^{*}$ Correspondence to: Sarah Gauci, Centre for Human Psychopharmacology, Swinburne University of Technology, 400 Burwood Rd, Hawthorn 3122, Australia. Tel.: +61 39214 5044; E-mail: sarahgauci@swin.edu.au.

\section{INTRODUCTION}

The growing number of elderly people [1] has resulted in increasing numbers of people living with 
age-related diseases such as dementia, cardiovascular disease, and metabolic syndrome [2-5]. However, the development of such non-communicable disorders is not an inevitable part of senescence. Increasing research suggests that modifiable lifestyle factors such as diet can delay the onset and progression of age-related diseases [6-9].

At a population level, aging is associated with a decline in cognitive abilities. However, the extent of cognitive decline is subject to wide interindividual variation $[10,11]$. Some individuals reach old age with their cognitive abilities relatively intact while others develop cognitive aging disorders such as Alzheimer's disease (AD). The development of $\mathrm{AD}$ has a long preclinical stage where the biological markers of the disease are present for years, possibly decades, before diagnosis [12, 13]. As there are no effective treatments once a clinical diagnosis is reached, evidence suggests targeting the preclinical stage with intervention strategies may be a more effective strategy to combat AD [12].

Diet has been proposed as a possible intervention strategy during the preclinical stages of $\mathrm{AD}$ as it has been linked to many aspects of health including cognitive performance. Research has shown that 'healthy diets' assessed using measures of diet quality or adherence to dietary patterns, such as the Mediterranean diet, Dietary Approaches to Stop Hypertension (DASH) diet, the MediterraneanDASH diet intervention for neurodegenerative delay, (MIND) diet, and prudent style diet (PSD), have been associated with reduced risk of cognitive decline [14-19] and improved cognitive performance after dietary intervention [20-22]. However, Australians predominantly do not adhere to these healthy dietary patterns. On average, Australians are exceeding recommendations for discretionary food and only $4 \%$ are meeting the recommended daily intake of vegetables and legumes [23, 24]. This suggests that the typical Australian diet is more consistent with a Western Style Diet (WSD), which comprises a high intake of processed foods, red meat, processed meats, saturated fat, full-fat dairy, alcohol and refined sugars; reduced consumption of complex carbohydrates, fiber intake, fruit and vegetables [25, 26]. Even though adherence to the WSD is increasing globally, research on how this dietary pattern affects cognitive performance is limited when compared to healthy dietary patterns [18, 27, 28]. However, adherence to the WSD and similar dietary patterns have been related to accelerated decline in visuospatial functioning [26] and poorer vocabulary and semantic fluency [29].
Another way to capture the complex nature of diet is to measure diet quality which assesses overall nutritional risk for future disease [30]. Poorer diet quality which is associated with the WSD has been found to be related to impaired cognition [31], while an optimal diet has been related to better cognitive processing [32].

Diet quality and adherence to various dietary patterns have also been related to cardiovascular health. For example, higher diet quality has been found to reduce the risk of cardiovascular disease [33, 34], whereas adherence to the WSD has been linked to increased risk of cardiovascular disease [35]. Cardiovascular function may be an important mechanisms underpinning the relationship between diet and cognition as it is also related to cognitive function [36, 37]. Arterial stiffness is a useful measure of cardiovascular health and function. During aging arterial walls change from a relatively 'elastic' to a more 'inelastic' state termed 'arterial stiffness'. This results in an increase in pressure wave reflections that arrive back to the heart augmenting the aortic pressures $[38,39]$. Higher arterial stiffness is associated with poorer cognitive performance, with higher predictive validity in comparison to other cardiovascular health markers such as brachial blood pressure [40, 41]. As arterial stiffness is a well establish risk factor for cognitive decline and is also related to diet [40], diet may be a moderating factor in the relationship between arterial stiffness and cognitive health.

Diet is also a possible moderating factor in the relationship between glucose control and cognitive health. As a hallmark of metabolic syndrome and diabetes, poor glucose control and insulin resistance have also been found to be related to worse cognitive performance and increased risk of dementia in both healthy individuals and those with diabetes [42-46]. Specifically, increased glycated hemoglobin (HbAlc), a measure of glucose control over the preceding 8-12 weeks, has been related to declines in episodic memory in both people with and without diabetes [47], declines in the performance on the Mini-Mental State Examination (MMSE) in people without diabetes [48] and reduced hippocampal and frontal brain volumes in adolescents with diabetes [49]. The relationship of glucose control with both cognition and diet $[50,51]$ suggests that diet may also have a moderating effect on the relationship between glucose control and cognition.

The current body of evidence supports the link between diet and various cardio-metabolic risk factors with cognitive decline. However, little is known 
about the mechanisms underpinning diet and how it may interact with other risk factors to have a combined, perhaps even synergistic effect on cognition. The present study aimed to explore the relationship between diet (specifically diet quality and adherence to both the WSD and PSD) and cognitive performance in a non-clinical population of older adults at risk of cognitive decline [12, 52]. It is hypothesized that greater diet quality and adherence to PSD will be related to improved cognitive performance, whereas greater adherence to the WSD will be related to poorer cognitive performance. The study also aimed to explore whether glucose control and arterial stiffness are related to cognitive performance in a population free of diabetes and cardiovascular disease and whether diet moderates the relationships of glucose control and arterial stiffness with cognitive performance. However, the study was powered for at most one interaction and this was chosen to be the interaction between arterial stiffness and adherence to the PSD. While the literature supports possible interactions between diet and both measures of cardio metabolic risk. Arterial stiffness and PSD were chosen as the primary interaction to extend the work of Kennedy et al. (2018) [53], which explored how arterial stiffness and lifestyle factors impact cognition in a similar sample older Australian adults. All other interaction analyses were regarded as exploratory.

\section{MATERIALS AND METHODS}

The present study analyzed baseline data from an existing clinical trial: Phospholipid Intervention for Cognitive Aging Reversal (PLICAR) conducted at the Centre for Human Psychopharmacology at Swinburne University, Melbourne, Australia. This clinical trial was registered with the Australian New Zealand Clinical Trials Registry (ACTRN12613000347763). The aim of the PLICAR trial was to investigate the effects of a dietary intervention on cognition and health in older individuals at risk of future cognitive decline, the results of which will be published elsewhere (for more details on the randomized controlled trial, see [54]). The present investigation is an exploratory cross-sectional examination of the relationship between diet, arterial stiffness, glucose control, and cognitive performance prior to administering the intervention. The study was approved by the Swinburne University Human Research Ethics Committee (SUHREC Project No. 2012/294).

\section{Participants}

There were 163 participants $(M=65.23$ years, $S D=6.50$ ) who completed testing for the study. They were recruited through the Centre for Human Psychopharmacology database of existing participants, community flyers, and internet advertisements. Interested participants were initially screened via telephone as a preliminary assessment of eligibility. Participants were excluded from the study if they were below 55 years of age, diagnosed with any neurological disorders, diabetes, heart disease, bleeding disorders, psychiatric illnesses, depression, or dementia. To assess risk of future cognitive decline, participants were also screened to ensure that they met Crook et al.'s [52] criteria for age associated memory impairment using the Verbal Paired Associates (VPA) test [55] and Memory Complaint Questionnaire [56]. A maximum score of 32 on the VPA was used to screen for objective memory impairment and a minimum score of 25 on the MAC-Q [56] was use to screen for subjective memory complaints. This ensured that participants had self-reported memory complaints and scored at least one standard deviation below the mean for memory as measured on the VPA, suggesting future risk of further cognitive decline.

The initial phone screening was conducted as a preliminary assessment of eligibility and discussion outlining what participation involved. If eligible following the telephone screen, the participant was scheduled for a practice session which included additional screening measures to finalize eligibility. It included written informed consent, the MMSE [57], and the Beck Depression Inventory-II (BDI-II) [58]. The session also allowed participants to familiarize themselves with the study procedures through a practice trial of computerized cognitive assessments (SUCCAB). Administration of the Food Frequency Questionnaire (FFQ) was also completed during the practice session. The baseline testing session was conducted on average 20.17 ( \pm 21.65$)$ days after the practice session. Participants were asked to fast from $10 \mathrm{pm}$ the night before and abstain from any alcohol (for $12 \mathrm{~h}$ prior to testing) and caffeinated beverages (on the day of testing). On arrival, a fasting blood sample was collected by a registered research nurse or a qualified venipuncture technician. The blood sample was then sent to a pathology laboratory for analysis of HbA1c levels. Following this, the participant was provided with a standard light breakfast followed by a 15 min break. During the testing session, participants 


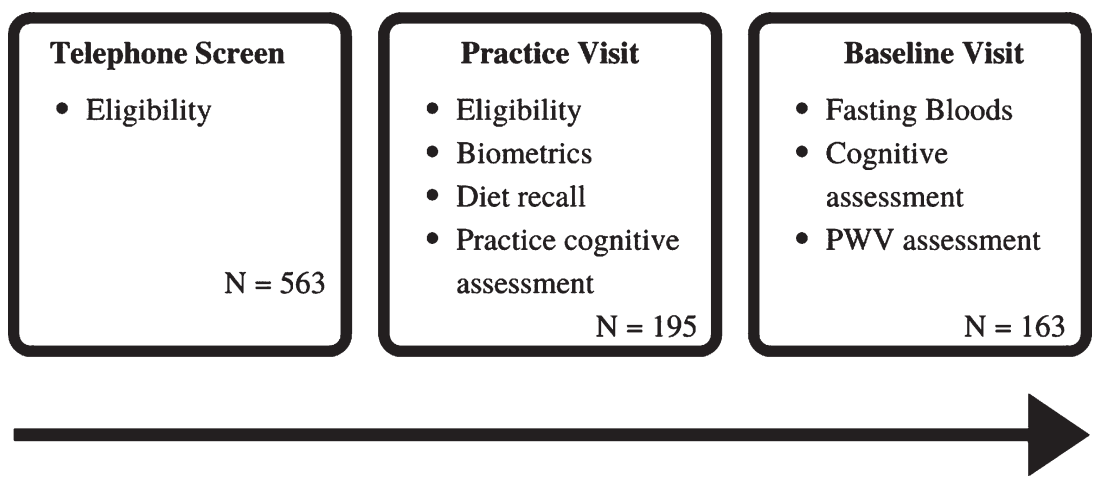

Fig. 1. Schedule of assessments from the PLICAR trial used in the current analysis.

completed the cognitive assessments (SUCCAB and RVLT). An outline of assessments is displayed in Fig. 1.

\section{Diet}

To measure nutritional intake, the Food Frequency Questionnaire (FFQ) from the Cancer Council Victoria was used $[59,60]$. This FFQ is a well validated and reliable measure of habitual dietary intake in an Australian population [61, 62]. It assesses frequency of consumption and average serving size of 74 different food items and six alcoholic beverages over the last 12 months. Estimations of daily intake for each food item were calculated in grams per day based on the reported portion size. Total energy $(\mathrm{kJ})$ intake per day was computed based on the AUSNUT 2007 nutrient database [63].

Responses on the FFQ were used to score adherence to the Western Style Diet (WSD) and Prudent Style Diet (PSD), based on the method used by Gardener et al. [26]. This method was chosen as Gardener et al. used the same FFQ $[59,60]$ as the current study and it was conducted in a similar cohort of elderly Australian individuals. Supplementary Tables 1 and 2 outline the food items in each of the WSD and PSD factors developed by Gardener et al. Adherence was scored by multiplying consumption of each food group (grams per day) with its corresponding factor loading and adding these values together. A higher score indicates greater adherence to each respective dietary pattern [26].

In addition to scoring adherence to these two dietary patterns, overall diet quality was assessed using the Australian version of the Diet Screening Tool (DST) [30, 64]. The tool comprised twenty items and has a maximum score of 104 , with a higher score reflecting better diet quality [30, 64]. It has recently been found to differentiate nutrient intake, blood nutrient status, mood, and cognition in Australian middle-aged adults [32]. Frequency data from the FFQ was used to score diet quality from the DST. As no frequency data was available for olive oil intake, this question was omitted, changing the overall maximum score to 99 (range: 0-99). As the DST is a validated measure of diet quality, Pearson's correlations were conducted to demonstrate that both the WSD and PSD measure low and high diet quality respectably. The WSD was negatively correlated with DST $(r=-0.392, p<0.001)$, whereas the PSD was positively correlated with the DST $(r=0.437$, $p<0.00$ ).

\section{Arterial stiffness assessment}

Arterial stiffness was assessed using carotidfemoral pulse wave velocity (cf-PWV). This was measured using the SphygmoCor ${ }^{\circledR}$ device (Model XCEL, AtCor Medical, Sydney, Australia). Cf-PWV was calculated using a femoral cuff. This cuff measures the pressure pulse waveform from the femoral artery. While the participant was supine, the cuff was inflated to measuring the pulse pressure waveform from the femoral artery and the research assistant concurrently measured the carotid waveform using a pressure tonometer probe (placed on the participant's neck/ carotid pulse). The distance between the two points (carotid \& femoral) were measured to estimate the speed of the pressure pulse. cf-PWV is a well validated method and is considered the gold standard for non-invasive arterial stiffness assessment $[65,66]$. For each participant two cf-PWV recordings were made, the recordings were then reviewed by SG and the recording with the lower standard deviation was 
selected for analysis. For participants with two cfPWV recordings with the same standard deviation, the score was averaged.

\section{Glucose control}

Fasting hematological testing was conducted at the start of the visit to assess glucose control. Preprocessing was completed on site where possible, samples were then couriered to a commercial pathology laboratory for analysis. Glucose control was specifically measured using the blood marker glycated hemoglobin (HbA1c). As this measure reflects average blood glucose levels in the preceding 8 to 12 weeks [67], elevated $\mathrm{HbA1c}$ indicates poorer glucose control. Studies have suggested that glucose control should be measured and reported in the standardized International Federation of Clinical Chemistry and Laboratory Medicine units (IFCC) [68, 69]. Normal levels of HbA1c are defined as between $20-42 \mathrm{mmol} / \mathrm{mol}$ and levels above $46 \mathrm{mmol} / \mathrm{mol}$ are considered to be an indicator of diabetes [69].

\section{Cognitive outcomes}

\section{Swinburne university computerized cognitive assessment battery (SUCCAB)}

The SUCCAB is a well validated and reliable measure of cognitive functioning in older adults [70]. The full battery was designed to measure performance accuracy and response time across eight different measures of cognitive functioning. Contextual Memory $(\mathrm{CM})$ and Spatial Working Memory (SWM) are two of the most sensitive tests of age-associated cognitive decline [70]. Both tasks are sensitive to change through dietary intervention $[21,71,72]$. The current study focused on the performance outcomes for these two tests. SWM measures the ability to hold spatial information in working memory whereas $\mathrm{CM}$ measures an aspect of contextual episodic memory for everyday objects [70].

Testing was conducted using a color computer monitor and responses were recorded using a standard keyboard with the keys A and L labelled to indicate yes/no responses respectively and the arrow keyboard buttons were also used. For both the SWM and CM tasks, written and verbal instructions were provided to participants as well as a practice trial to allow participants to familiarize themselves with the test and response method.

The SWM task of SUCCAB begins with the presentation of a $4 \times 4$ grid on the screen, with six a.

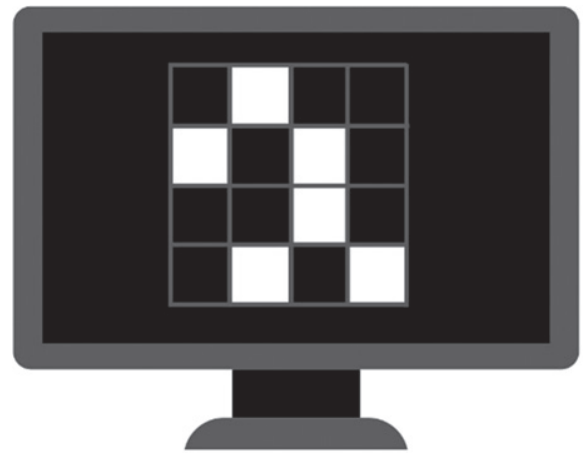

b.

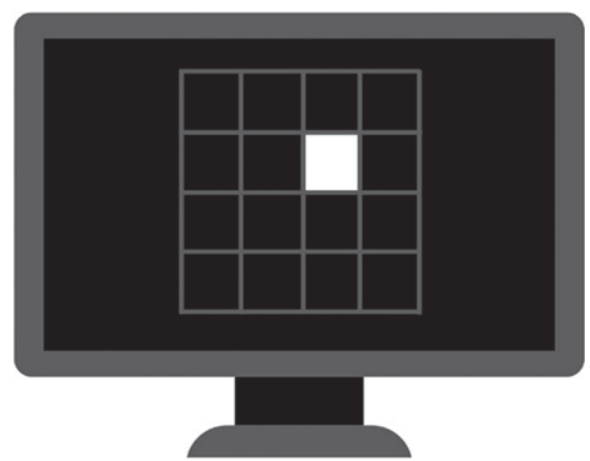

Fig. 2. Spatial working memory task. a) The $4 \times 4$ grid on the screen contacting six random grid white squares. B) A single white square is presented in on the grid. Participants required to respond 'yes' or 'no' to indicate if square was in one of the locations of the original pattern.

random grid positions containing white squares for $3 \mathrm{~s}$ (see Fig. 2a). Following this, a series of single white squares are sequentially presented in different locations on the grid. Participants were required to respond 'yes' or 'no' on a labelled keyboard to indicate if they believe the single test square was in one of the locations of the original pattern (see Fig. 2b). Participants had $2 \mathrm{~s}$ to respond if they took longer, it was marked as incorrect.

During the CM task, participants were presented with a series of 20 colored images of everyday objects. These images were presented at different locations on the screen, either the top, bottom, left or right; each image was displayed for $3 \mathrm{~s}$ with no inter-stimulus interval (see Fig. 3a). Once the series of images were all presented, a second set of the same pictures were presented in the center of the screen and participants were required to indicate where the original image was located using the arrow keys on the keyboard (see Fig. 3b).

The results from the correctly performed trials were averaged to provide an overall mean reaction 


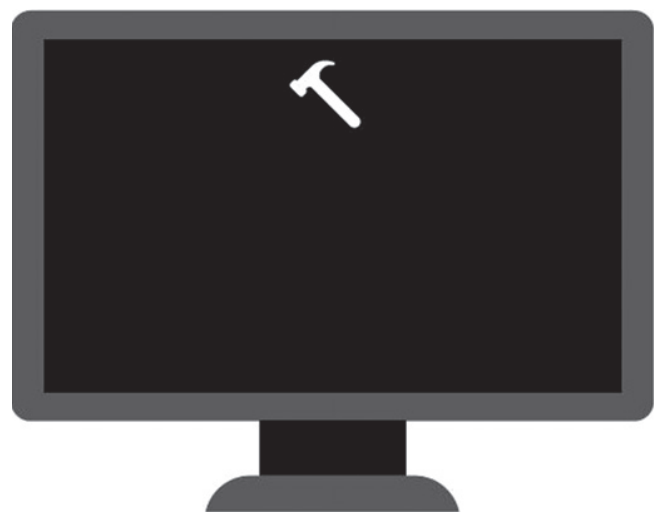

b.

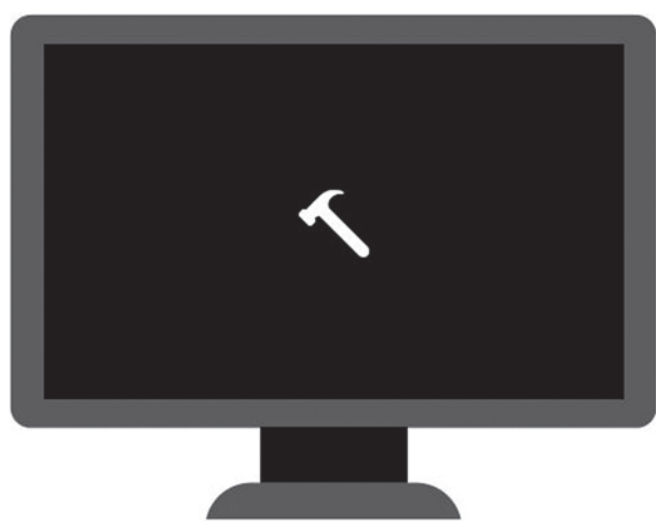

Fig. 3. Contextual memory. a) Example of an everyday object presented on the top of the screen. b) Example of the same everyday object presented in the second set, participants was required to indicate original located using the arrow keys on the keyboard.

time in milliseconds for each test. Response accuracy was calculated for both SWM and CM as the percentage of the correctly performed trials. Performance scores for both the SWM and CM subtests were calculated by dividing accuracy by reaction time with higher scores indicative of better performance.

\section{Rey's verbal learning test (RVLT)}

In addition to the SUCCAB, RVLT was also used to assess cognitive performance. RVLT is a well validated and reliable test of verbal learning and memory $[73,74]$. Measures of memory and verbal memory have been found to be sensitive to age associated cognitive decline and have been found to be sensitive to different dietary patterns and dietary intervention $[75,76]$.

During the RVLT test, the experimenter read a list of 15 words to the participant in a fixed sequence, with one word every $2 \mathrm{~s}$. After the presentation of the sequence, participants were asked to recall as many of the words as they could. This immediate recall process was repeated five times and following this there was a 20 min delay during which participants completed other cognitive assessments. After the delay participants were asked to recall as many words as they could remember from the original list.

There were three performance scores for this measure: Total immediate recall was the summed total number of words recalled for the first five trials (scores ranged from 0-75). Maximum immediate recall was the highest number of words recalled during the first five trials (scores ranged from 0-15) and Delayed recall was the number of words recalled in the sixth trial (scores ranged from 0-15) [74, 77]. A memory composite score was also calculated using the same method as Durga et al., the $z$ scores for each of the outcomes were added together and divided by three [77].

\section{Data analyses}

All data analyses were conducted using SPSS version 27. Demographic data were presented using the mean and standard deviation. All data used in the current analysis met assumptions for regression, so no transformation was needed. Z scores were calculated for each variable, scores greater than 3.29 or scores greatly disconnected from the spread of the data were considered outliers and excluded from subsequent analysis. A series of two stage hierarchical regressions were conducted with the covariates entered at stage one and the independent variables (PSD, WSD, DST, cf-PWV, and HbA1c) entered at stage two. Dependent variables were the performance outcomes for SUCCAB and RVLT. Covariates were age (in years), gender, years of education, energy intake (kJ), and body mass index (BMI; weight in kilograms/height in $\mathrm{m}^{2}$ ). These covariates have been found to be related to cognition in the past $[53,70$, 78-83]. All the covariates except for gender were included in the model as continuous variables. Significance was set at a 5\% level.

Following primary analyses, additional sequential multiple regression analyses were conducted to test for diet and cardio-metabolic risk interaction effects. Firstly, the dietary, glucose and, arterial stiffness measures were centered, allowing for interaction terms to be computed. The interaction terms were then computed by multiplying two centered variables together (e.g., for the interaction between PSD and arterial stiffness these two centered measures were multiplied together). For the multiple regressions, the covariates 
Table 1

Summary of means and standard deviations for all variables

\begin{tabular}{lccccc}
\hline Variable & $N$ & $M$ & $S D$ & Min & Max \\
\hline Demographic & & & & & \\
Age (y) & 163 & 65.23 & 6.50 & 55.00 & 84.00 \\
Years of Education & 163 & 15.14 & 3.42 & 5.00 & 23.00 \\
BMI (kg/m ${ }^{2}$ ) & 162 & 28.21 & 4.98 & 18.00 & 46.11 \\
Diet & & & & & \\
$\quad$ WSD score & 157 & 178.20 & 137.23 & -76.93 & 629.75 \\
$\quad$ PSD score & 157 & 234.85 & 127.45 & -165.27 & 560.04 \\
DST & 158 & 67.58 & 9.31 & 38.00 & 85.00 \\
Energy (kJ) & 157 & $7,220.36$ & $2,255.77$ & $3,367.35$ & $10,795.40$ \\
Glucose control & & & & & \\
$\quad$ HbA1c (mmol/mol) & 153 & 37.03 & 3.66 & 28.00 & 46.00 \\
Arterial Stiffness & & & & & \\
$\quad$ cf-PWV (m/s) & 149 & 10.71 & 1.75 & 6.00 & 15.6 \\
Cognitive Variables & & & & & \\
$\quad$ SUCCAB & & & & & \\
$\quad$ CM Performance & 162 & 67.83 & 17.30 & 27.58 & 113.19 \\
$\quad$ SWM Performance & 162 & 63.29 & 17.32 & 8.38 & 115.66 \\
$\quad R V L T$ & & & & & \\
$\quad$ Total immediate recall & 163 & 46.88 & 9.14 & 19.00 & 67.00 \\
$\quad$ Max immediate recall & 163 & 11.89 & 2.13 & 5.00 & 15.00 \\
$\quad$ Delayed recall & 163 & 8.87 & 3.13 & 0.00 & 15.00 \\
$\quad$ Memory composite & 163 & 0.00 & 0.94 & -2.89 & 1.87 \\
\hline
\end{tabular}

$M$, mean; SD, standard deviation; Min, minimum; Max, maximum; BMI, body mass index; WSD, Western style diet; PSD, Prudent style diet; DST, diet screening tool; HbA1c, Glycated hemoglobin; cf-PWV, Carotid to femoral Pulse wave velocity; SUCCAB, Swinburne University Computerized Cognitive Assessment Battery; CM, Contextual memory; SWM, Spatial Working Memory; RVLT, Rey's Verbal Learning Test.

(age, gender, years of education, energy intake $(\mathrm{kJ})$ and BMI) were entered at stage one, the two centered variables at stage two and the interaction term at stage three. Due to the small sample size only one of these interactions was tested for significance. A sample size estimation was conducted using $\mathrm{G}^{*}$ Power [84], finding that when using ten variables in a model (five covariates, five independent variables), a $1 \%$ significance level to allow for six cognition outcomes, an estimated effect size of $\mathrm{f}^{2}=0.15$ and power of 0.80 , a sample of 160 participants is required. In order to visualize the significant interactions, Cohen et al. (2003) suggest plotting the dependent variable at one standard deviation below the mean (low), at the mean (medium), and one standard deviation above the mean (high) for the predictor variables [85].

\section{RESULTS}

Means and standard deviations for the demographic variables and baseline measures for participants are presented in Table 1. Participants in the study had a mean age of 65.23 years, $46.6 \%$ of participants completed tertiary education, around half the participants were retired (49.7\%) with only $20.3 \%$ still working full time. On average participant BMI was above the healthy range $(M=28.21, S D=4.98)$, almost all participant had glucose control readings in the healthy range ( $\mathrm{HbA} 1 \mathrm{c}$ between $20-42 \mathrm{mmol} / \mathrm{mol}$ ) and of arterial stiffness measures were within two standard deviations of the norms for this age range [66]. All cognitive outcomes were negatively correlated with age $(p<0.007)$.

Standardized beta coefficients from cognition regression analyses examining the effects of adherence to diet quality, WSD, PSD, glucose control $(\mathrm{HbA} 1 \mathrm{c})$ and carotid femoral pulse wave velocity (cf-PWV) are presented in Table 2. Each model was adjusted for the covariates described above. Lower cf-PWV significantly predicted better SWM performance after controlling for age, gender, education, energy, BMI, and the other independent variables $(F$ Change $(5,127)=4.07, p=0.045)$. The model predicted a total of $16.8 \%$ of the variance in SWM, of which cf-PWV accounted for an additional $2.4 \%$ of this variance above and that explained by the other predictors. There were no other significant relationships between cognitive performance and the other independent variables.

In order to examine the interaction between the PSD and arterial stiffness, additional three stage 
Table 2

Association of diet, glucose control and PWV with cognitive performance, standardized coefficients beta

\begin{tabular}{|c|c|c|c|c|c|c|}
\hline & \multicolumn{2}{|c|}{ SUCCAB } & \multicolumn{4}{|c|}{ RVLT } \\
\hline & $\begin{array}{l}\text { SWM } \\
\text { Per }\end{array}$ & $\begin{array}{l}\text { CM } \\
\text { Per }\end{array}$ & $\begin{array}{c}\text { Total } \\
\text { immediate } \\
\text { recall }\end{array}$ & $\begin{array}{c}\text { Maximum } \\
\text { immediate } \\
\text { recall }\end{array}$ & $\begin{array}{c}\text { Delayed } \\
\text { recall }\end{array}$ & $\begin{array}{l}\text { Memory } \\
\text { Composite }\end{array}$ \\
\hline WSD & -0.033 & -0.009 & 0.079 & 0.083 & 0.077 & 0.085 \\
\hline PSD & -0.031 & 0.087 & -0.035 & -0.041 & -0.025 & -0.036 \\
\hline DST & -0.007 & 0.044 & -0.059 & -0.039 & -0.062 & -0.057 \\
\hline $\mathrm{HbA1c}$ & -0.128 & -0.122 & -0.074 & -0.026 & -0.076 & -0.128 \\
\hline Cf-PWV & $-0.211^{*}$ & -0.043 & -0.025 & -0.039 & -0.108 & -0.062 \\
\hline
\end{tabular}

${ }^{*} p<0.05 N=163$, Model adjusted for age, gender, education, energy intake, BMI. WSD, Western style diet; PSD, Prudent style diet; DST, diet screening tool; HbA1c, Glycated hemoglobin; cf-PWV, Carotid to femoral Pulse wave velocity; SUCCAB, Swinburne University Computerized Cognitive Ageing Battery; CM Per, Contextual memory performance; SWM Per, Spatial Working Memory performance; RVLT, Rey's Verbal Learning Test.

hierarchical regressions were conducted. There was a significant interaction between PSD and cf-PWV for RVLT total immediate recall. While the control variables predicted $22 \%$ of the variance in RVLT total immediate recall $(F$ Change $(5,137)=7.720$, $p<0.001)$, the inclusion of the PSD and cf-PWV predicted an additional $0.1 \%$ of the variance ( $F$ Change $(2,135)=0.106, p=0.899)$. Finally, the addition of the interaction term at stage three predicted an additional $3 \%$ of the variance $(F$ Change $(1,134)=5.367$, $p=0.022$ ). There was also a significant interaction between PSD and cf-PWV for the composite score for RVLT. The control variables were found to predict $18.8 \%$ of the variance in RVLT composite score $(F$ Change $(5,137)=6.343, p<0.001)$. The inclusion of the PSD and cf-PWV predicted an additional $0.4 \%$ of the variance $(F$ Change $(2,135)=0.309, p=0.734)$. Finally, the addition of the interaction term at stage three predicted an additional $2.4 \%$ of the variance ( $F$ Change $(1,134)=4.034, p=0.047)$. These two interaction effects are illustrated in Fig. 4.

Additional exploratory interactions were conducted for the other dietary patterns and diet quality with arterial stiffness and glucose control. However, there were no significant interactions between WSD and cf-PWV, WSD and HbA1c, Diet quality and PWV, and diet quality and HbAlc for any of the cognitive outcomes. The results did not differ when removing BMI as a covariate.

\section{DISCUSSION}

In this cross-sectional study of Australian older adults who may be at risk for future cognitive decline, we found that when studied as independent predictors, diet quality and adherence to either the a.

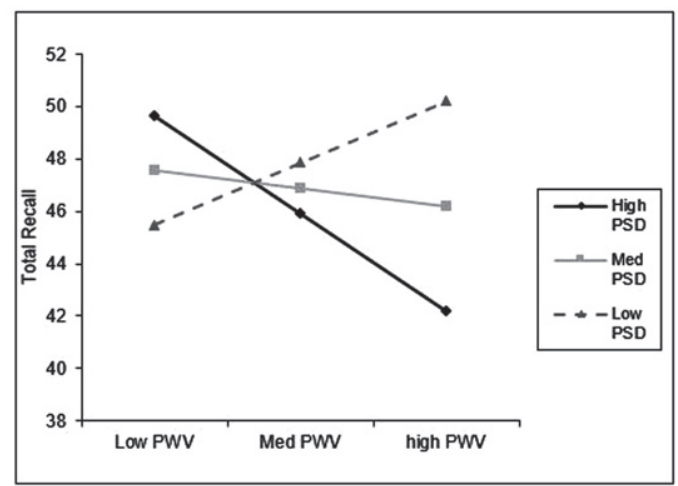

b.

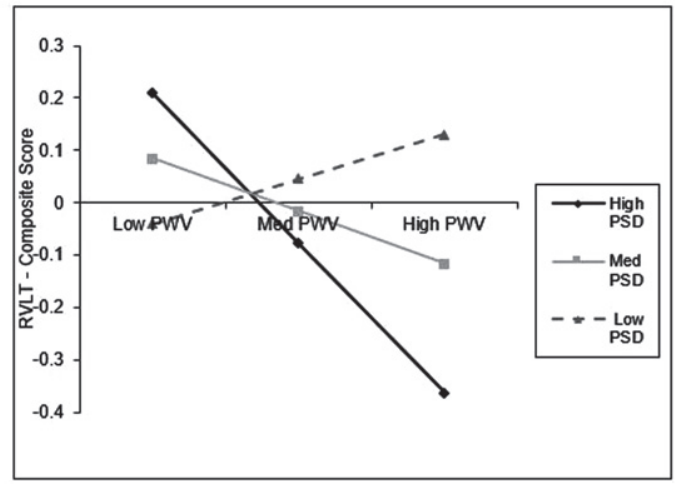

Fig. 4. Interaction plot for selected cognitive tasks (significant). a) a. total recall across low, medium, and high levels of PSD and PWV. b) RVLT composite score across low, medium, and high levels of PSD and PWV. Low = one standard deviation below the mean (PSD: $\mathrm{N}=31$, PWV: $\mathrm{N}=21$ ); Medium = mean value; High = one standard deviation bove the mean (PSD: $\mathrm{N}=30, \mathrm{PWV}: \mathrm{N}=23$ ).

WSD or PSD were not significantly related to cognitive performance. Likewise, there was no significant association between glucose control and cognitive performance. However, cf-PWV, a measure of arterial stiffness, was found to be a significant predictor of SWM performance, a measure that has been found to 
be sensitive to age associated cognitive decline [70]. We also found that cf-PWV significantly interacted with PSD to impact cognitive performance for total recall and the composite score of RVLT. To the best of the author's knowledge, this is the first study to investigate the inter-relationship between the diet, arterial stiffness, glucose control, and cognitive performance.

The relationship observed between arterial stiffness and SWM is consistent with previous research. Kennedy et al. identified a significant association between cf-PWV and SWM performance scores in older adults. They found that cf-PWV (along with fitness) mediated the association between age and SWM performance [53]. Others have made similar observations regarding arterial stiffness and cognitive performance in older adults $[41,86]$ and in middle aged adults [87]. The participants in the current study were free from cardiovascular disease, indicating that even in individuals with 'healthy' cardiovascular function, elevated arterial stiffness may have implications for cognitive performance, particularly working memory.

Contrary to expectations we did not find a significant relationship between either of the dietary patterns or diet quality with cognitive performance. While there is evidence to support a link between diet and cognitive performance $[16,18,88]$, data from other studies appears ambiguous or even contrary [89-91]. Gardener et al. [26] also failed to link adherence to the PSD with cognitive performance, though the Mediterranean style diet and WSD were found to impact cognition. They suggested that despite adherence to a PSD reflecting that of the Mediterranean style diet, adherence to a PSD may not relate to cognition due to a reduced emphasis on fish consumption and subsequent intake of long chain omega-3 fatty acids. Further, the even though the current sample is of older adults, the mean age of 65years may not be old enough to detect a significant impact of diet on cognition. Another suggestion which may partially explain the results of the present study is that different dietary patterns may interact, and in turn, cancel out their effect on cognition. While the majority of past research has investigated adherence to a singular dietary pattern at a time, people tend to consume a variety of foods that may score on multiple dietary patterns and these different foods may interact to impact cognitive performance. For example, Shakersain et al. previously reported that adherence to the PSD attenuated the effects of the WSD on cognitive performance [92]. Another more recent study also found that the adherence to a WSD attenuates the protective role of the Mediterranean diet on cognitive decline [93]. Further, the current method of measuring diet may not be detailed enough to capture the current dietary patterns of the population under investigation. Participants may be adhering to another dietary pattern or variation of the WSD or PSD that was not captured by the FFQ used. In addition, the 20-item DST used to measure diet quality may not have sufficient detail to identify adequate nutrition risk in this population. All of these factors may have contributed to the present study failing to link diet as an independent predictor of cognitive performance.

This study is also the first to investigate how diet interacts with risk factors for cognitive decline to impact cognitive performance. The significant interaction for RVLT total recall suggests that for those with high adherence to the PSD, lower cf-PWV is conducive to better cognitive performance than is higher cf-PWV. This suggest that diet may not impact cognitive performance in isolation, rather its relationship with brain health may be due to complex interaction with other risk factors. Unexpectedly, individuals with low adherence to the PSD and high cf-PWV perform better than those with low adherence and low cf-PWV. This unusual relationship may be because low adherence to either diet pattern only provides information about what individuals are not consuming [26]. As a result, it is unclear what aspects of diet could be contributing to the relationship observed when looking at low adherence. It can also be observed in Fig. 4 that those with high adherence to the PSD and high PWV have the worst cognitive performance. This finding, while unexpected, suggests that once significant pathology has occurred (i.e., greater arterial stiffness), diet does not have a protective role for cognitive performance. The significant interaction between PSD and cf-PWV for the RVLT composite score indicates reduced variance in cognitive performance for individuals with low adherence to the PSD regardless of cfPWV status, though individuals with lower cf-PWV appeared to demonstrate the worst performance. Conversely, there was markedly greater variance in RVLT composite score for individuals demonstrating high adherence to the PSD, with individuals concurrently demonstrating lower cf-PWV outperforming those with poorer cf-PWV (see Fig. 4). The combined interactions between the PSD and cf-PWV suggests that the PSD may not be an independent factor predicting cognitive performance but may operate in conjunction with measures of central arterial stiffness (e.g., cf-PWV). Future research should investigate more 
cardio protective dietary patterns such as the Mediterranean diet or the DASH diet in conjunction with cognitive and cardiovascular function, especially as the PSD was not found to have a beneficial effect for those with higher arterial stiffness.

Though there were only two significant interactions, the findings of this study provide important evidence that the risk factors for cognitive decline do not work in isolation. Another study to explore the interdependent relationships between various risk factors for cognitive decline and brain health was conducted by Mosconi et al. (2018) [94]. They found that diet and insulin sensitivity explained variability in cortical thickness, and this was then related to memory performance. The findings from this study and the current findings suggest that future research must consider these interactions between risk factors. This will help us better understand how these factors impact cognition and may enable intervention programs to be tailored to individuals needs and prioritizing those who will best benefit from lifestyle intervention.

The current study has several limitations. Firstly, the use of a cross sectional design does not allow for the assessment of cause and effect relationships. Therefore, all current findings need confirmation through both longitudinal studies and trials. Secondly, the sample size is relatively small in comparison to large cohort studies. This therefore limited the number of participants demonstrating WSD, PSD, diet quality scores, cf-PWV or HbA1c levels greater than one standard deviation above the mean for these factors. This prevented a slope analysis from being conducted and subsequent exploration of whether there were significant differences between levels of adherence to dietary patterns, cf-PWV and HbA1c levels. Thirdly, sole reliance on the FFQ limited the extent to which dietary adherence or quality could be assessed. Dietary analysis based on participant recall, a defining characteristic of an FFQ, is prone to error. This would be an especially pertinent limitation given the study involved participants who had self-reported memory complaints [26, 52]. Given these participants subjectively report issues with their memory, the accuracy at recalling the foods consumed over the last 12 months cannot be guaranteed. In order to address this limitation, future research should seek to utilize nutrient biomarkers such as those used by Bowman et al. to compliment data derived from FFQs [95]. Moreover, the FFQ used in the current study does not provide an indication as to the frequency, or amount, to which sugary sweetened beverages and olive oil is consumed. This is problematic as sugary beverages are consumed in high amounts in Australia [23] and have been found to increase the risk of stroke and dementia [96] and therefore potentially impact cognitive function, particularly in older adults. Likewise, olive oil has also been found to play an important role in healthy dietary patterns such as the Mediterranean diet and has been shown to play a protective role in regards to cognitive function [97, 98]. Further, the weighting of the food groups for the PSD (Supplementary Table 2) suggest that this dietary pattern may be over representing fruit and vegetable intake over other food groups. The current study only controlled for age, gender, education, and energy intake and BMI. Additional factors such as physical activity and participation in cognitive activities may also impact the relationship. Therefore, future studies should control for these measures as well. Finally, the current study considered results significant at the $p<0.05$ level and did not correct for multiple comparisons, this needs to be taken into account when interpreting the findings as they may be due to chance.

Despite these limitations, the current study possessed a number of strengths. These include the use of covariates known to impact cognitive performance, diet, and cardiovascular and metabolic health. The use of age sensitive measures of cognition (SUC$\mathrm{CAB}$ and RVLT) are advantageous for detecting subtle associations between cognitive performance compared to generalized cognitive measures (e.g., MMSE) routinely utilized in aging research. The use of both SUCCAB and RVLT in the current study also allows for an increased number of cognitive domains to be assessed. Additionally, the use of a whole diet analysis is superior to investigating the individual food groups alone, as whole dietary analysis more accurately reflects real world food and nutrient consumption $[92,99]$. Aside from dietary adherence, diet quality was also assessed to capture the overall nutritional risk of participants. Diet quality has been investigated as a predictor of cognitive function $[31,100]$ and may represent an important predictor of brain tissue integrity in older adults [101].

\section{CONCLUSION}

In this sample of older Australian adults at risk for future cognitive decline, diet alone was not an independent predictor of cognitive performance, but rather interacted with arterial stiffness (i.e., cf-PWV). Arterial stiffness was also found to significantly 
predict cognitive performance independently; however, no relationship was observed between glucose control and cognitive outcomes. The current study provides further evidence that diet and arterial stiffness may not be acting in isolation, but rather in a combined, perhaps even synergistic fashion. In particular, the findings from this study provide additional evidence that diet may be acting through cardiovascular health to impact cognition. Exploring how dietary factors interact with other important health factors (e.g., physical activity), may provide valuable information in regard to the progression of cognitive decline and how these factors could be modified to reduce the impact of unhealthy brain aging.

\section{ACKNOWLEDGMENTS}

The authors would like to thank Renee Rowsell, Rebecca King, Naomi Perry, Katheryn Cox, and Helen Macpherson for administrative support, oversight, and help setting up the RCT. The resources of Centre for Human Psychopharmacology, Swinburne University of Technology, Melbourne, were used to conduct this study. The authors would also like to express our gratitude to the participants who volunteered their time for this study.

This study received funding from Arla Foods Ingredients Group P/S, Denmark. S.G. is funded by Australian Research Training Program Stipends. Arla Foods Ingredients Group P/S, Denmark had no role in the design of the study; in the collection, analyses, or interpretation of data; in the writing of the manuscript, or in the decision to publish the results.

Authors' disclosures available online (https:// www.j-alz.com/manuscript-disclosures/21-0567r2).

\section{SUPPLEMENTARY MATERIAL}

The supplementary material is available in the electronic version of this article: https://dx.doi.org/ 10.3233/JAD-210567.

\section{REFERENCES}

[1] United Nations, Department of Economic and Social Affairs PD (2019) WPA 2019: H (ST/ESA/SER. World Population Ageing 2019 Highlights.

[2] Levy R (1994) Aging-associated cognitive decline. Int Psychogeriatr 6, 63-68.

[3] Laurent S, Boutouyrie P, Lacolley P (2005) Structural and genetic bases of arterial stiffness. Hypertension 45, 10501055.
[4] World Health Organization (2016) Global Report on Diabetes.

[5] Deary IJ, Corley J, Gow AJ, Harris SE, Houlihan LM, Marioni RE, Penke L, Rafnsson SB, Starr JM (2009) Age-associated cognitive decline. Br Med Bull 92, 135-152.

[6] Pérez-Martínez P, Mikhailidis DP, Athyros VG, Bullo M, Couture P, Covas MI, de Koning L, Delgado-Lista J, Díaz-López A, Drevon CA, Estruch R, Esposito K, Fitó M, Garaulet M, Giugliano D, García-Ríos A, Katsiki N, Kolovou G, Lamarche B, Maiorino MI, Mena-Sánchez G, Muñoz-Garach A, Nikolic D, Ordovás JM, Pérez-Jiménez F, Rizzo M, Salas-Salvadó J, Schrö der H, Tinahones FJ, de la Torre R, van Ommen B, Wopereis S, Ros E, López-Miranda J (2017) Lifestyle recommendations for the prevention and management of metabolic syndrome: An international panel recommendation. Nutr Rev 75, 307-326.

[7] Calder PC, Carding SR, Christopher G, Kuh D, LangleyEvans SC, McNulty H (2018) A holistic approach to healthy ageing: How can people live longer, healthier lives? J Hum Nutr Diet 31, 439-450.

[8] Peters R, Booth A, Rockwood K, Peters J, D’Este C, Anstey KJ (2019) Combining modifiable risk factors and risk of dementia, a systematic review and meta-analysis. BMJ Open 9, e022846.

[9] Yu E, Rimm E, Qi L, Rexrode K, Albert CM, Sun Q, Willett WC, Hu FB, Manson JAE (2016) Diet, lifestyle, biomarkers, genetic factors, and risk of cardiovascular disease in the nurses' health studies. Am J Public Health 106, 1616-1623.

[10] Christensen H, Kumar RK (2003) Cognitive changes and the ageing brain. In The Ageing Brain. CRC Press.

[11] Christensen $H$ (2001) What cognitive changes can be expected with normal ageing? Aust $N Z J$ Psychiatry 35, 768-775.

[12] Sperling RA, Aisen PS, Beckett LA, Bennett DA, Craft S, Fagan AM, Iwatsubo T, Jack CR, Kaye J, Montine TJ, Park DC, Reiman EM, Rowe CC, Siemers E, Stern Y, Yaffe K, Carrillo MC, Thies B, Morrison-Bogorad M, Wagster M V., Phelps CH (2011) Toward defining the preclinical stages of Alzheimer's disease: Recommendations from the National Institute on Aging-Alzheimer's Association workgroups on diagnostic guidelines for Alzheimer's disease. Alzheimers Dement 7, 280-292.

[13] Scharre DW (2019) Preclinical, prodromal, and dementia stages of Alzheimer's disease. Pract Neurol, pp. 36-47.

[14] Smith PJ, Blumenthal JA, Babyak MA, Craighead L, Welsh-Bohmer KA, Browndyke JN, Strauman TA, Sherwood A (2010) Effects of the dietary approaches to stop hypertension diet, exercise, and caloric restriction on neurocognition in overweight adults with high blood pressure. Hypertension 55, 1331-1338.

[15] Morris MC, Tangney CC, Wang Y, Sacks FM, Bennett DA, Aggarwal NT (2015) MIND diet associated with reduced incidence of Alzheimer's disease. Alzheimers Dement 11, 1007-1014.

[16] Hardman RJ, Kennedy G, Macpherson H, Scholey AB, Pipingas A (2016) Adherence to a Mediterranean-style diet and effects on cognition in adults: A qualitative evaluation and systematic review of longitudinal and prospective trials. Front Nutr 3, 22.

[17] Zhu N, Jacobs DR, Meyer KA, He K, Launer L, Reis JP, Yaffe K, Sidney S, Whitmer RA, Steffen LM (2015) Cognitive function in a middle aged cohort is related to 
higher quality dietary pattern 5 and 25 years earlier: The CARDIA Study. J Nutr Health Aging 19, 33-38.

[18] Chen X, Maguire B, Brodaty H, O'Leary F (2019) Dietary patterns and cognitive health in older adults: A systematic review. J Alzheimers Dis 67, 583-619.

[19] Shakersain B, Rizzuto D, Larsson S, Faxén-Irving G, Fratiglioni L, Xu W-L (2018) The Nordic Prudent Diet reduces risk of cognitive decline in the Swedish older adults: A population-based cohort study. Nutrients 10, 229.

[20] Lee J, Pase M, Pipingas A, Raubenheimer J, Thurgood M, Villalon L, Macpherson H, Gibbs A, Scholey A (2015) Switching to a 10-day Mediterranean-style diet improves mood and cardiovascular function in a controlled crossover study. Nutrition 31, 647-652.

[21] Hardman RJ, Meyer D, Kennedy G, MacPherson H, Scholey AB, Pipingas A (2020) Findings of a pilot study investigating the effects of Mediterranean diet and aerobic exercise on cognition in cognitively healthy older people living independently within aged-care facilities: The Lifestyle Intervention in Independent Living Aged Care (LIILAC) Study. Curr Dev Nutr 4, nzaa077.

[22] Cherian L, Fakuda K, Leuragans S, Aggarwal N, Morris M (2019) Mediterranean-Dash Intervention for Neurodegenerative Delay (MIND) diet slows cognitive decline after stroke. J Alzheimers Dis 6, 267-273.

[23] Hendrie G, Baird D, Golley S, Noakes M (2016) CSIRO Healthy Diet Score 2016.

[24] Australian Bureau of Statistics (2016) Australian Health Survey: Consumption of food groups from the Australian dietary guidelines.

[25] Francis H, Stevenson R (2013) The longer-term impacts of Western diet on human cognition and the brain. Appetite 63, 119-128.

[26] Gardener SL, Rainey-Smith SR, Barnes MB, Sohrabi HR, Weinborn M, Lim YY, Harrington K, Taddei K, Gu Y, Rembach A, Szoeke C, Ellis KA, Masters CL, Macaulay SL, Rowe CC, Ames D, Keogh JB, Scarmeas N, Martins RN (2015) Dietary patterns and cognitive decline in an Australian study of ageing. Mol Psychiatry 20, 860-866.

[27] Drewnowski A (2000) Nutrition transition and global dietary trends. Nutrition 16, 486-487.

[28] Gauci S, Young LM, Arnoldy L, Lassemillante A-C, Scholey A, Pipingas A (2021) Dietary patterns in middle age: Effects on concurrent neurocognition and risk of agerelated cognitive decline. Nutr Rev, doi: 10.1093/nutrit/ nuab047.

[29] Akbaraly TN, Singh-Manoux A, Marmot MG, Brunner EJ (2009) Education attenuates the association between dietary patterns and cognition. Dement Geriatr Cogn Disord 27, 147-154.

[30] Bailey RL, Miller PE, Mitchell DC, Hartman TJ, Lawrence FR, Sempos CT, Smiciklas-Wright H (2009) Dietary screening tool identifies nutritional risk in older adults. Am J Clin Nutr 90, 177-183.

[31] Fieldhouse JLP, Doorduijn AS, de Leeuw FA, Verhaar BJH, Koene T, Wesselman LMP, de van der Schueren M, Visser M, van de Rest O, Scheltens P, Kester MI, van der Flier WM (2020) A suboptimal diet is associated with poorer cognition: The NUDAD project. Nutrients $\mathbf{1 2}$, 1-10.

[32] Young LM, Gauci S, Scholey A, White DJ, Lassemillante A, Meyer D, Pipingas A (2020) Self-reported diet quality differentiates nutrient intake, blood nutrient status, mood, and cognition: Implications for identifying nutritional neurocognitive risk factors in middle age. Nutrients 12, 2964.

[33] Reedy J, Krebs-Smith SM, Miller PE, Liese AD, Kahle LL, Park Y, Subar AF (2014) Higher diet quality is associated with decreased risk of all-cause, cardiovascular disease, and cancer mortality among older adults. $J$ Nutr 144, 881-889.

[34] Atkins JL, Whincup PH, Morris RW, Lennon LT, Papacosta O, Goya Wannamethee S (2014) High diet quality is associated with a lower risk of cardiovascular disease and all-cause mortality in older men. J Nutr 144, 673-680.

[35] Fung TT, Rimm EB, Spiegelman D, Rifai N, Tofler GH, Willett WC, Hu FB (2001) Association between dietary patterns and plasma biomarkers of obesity and cardiovascular disease risk 1-3. Am J Clin Nutr 73, 61-67.

[36] Sierra C (2020) Hypertension and the risk of dementia. Front Cardiovasc Med 7, 5

[37] Dahle CL, Jacobs BS, Raz N (2009) Aging, vascular risk, and cognition: Blood glucose, pulse pressure, and cognitive performance in healthy adults. Psychol Aging 24, 154-162.

[38] Mitchell GF, Parise H, Benjamin EJ, Larson MG, Keyes MJ, Vita JA, Vasan RS, Levy D (2004) Changes in arterial stiffness and wave reflection with advancing age in healthy men and women: The Framingham Heart Study. Hypertension 43, 1239-1245.

[39] Chirinos JA (2012) Arterial stiffness: Basic concepts and measurement techniques. J Cardiovasc Transl Res 5, 243-255.

[40] Pase MP, Grima NA, Sarris J (2011) The effects of dietary and nutrient interventions on arterial stiffness: A systematic review. Am J Clin Nutr 93, 446-454.

[41] Singer J, Trollor JN, Baune BT, Sachdev PS, Smith E (2014) Arterial stiffness, the brain and cognition: A systematic review. Ageing Res Rev 15, 16-27.

[42] Biessels GJ, Staekenborg S, Brunner E, Brayne C, Scheltens P (2006) Risk of dementia in diabetes mellitus: A systematic review. Lancet Neurol 5, 64-74.

[43] Yaffe K, Falvey C, Hamilton N, Schwartz A V, Simonsick EM, Satterfield S, Cauley JA, Rosano C, Launer LJ, Strotmeyer ES, Harris TB (2012) Diabetes, glucose control, and 9-year cognitive decline among older adults without dementia. Arch Neurol 69, 1170-5.

[44] Crane PK, Walker R, Hubbard RA, Li G, Nathan DM, Zheng H, Haneuse S, Craft S, Montine TJ, Kahn SE, McCormick W, McCurry SM, Bowen JD, Larson EB (2013) Glucose levels and risk of dementia. Forsch Komplementarmed 20, 386-387.

[45] Craft S (2009) The role of metabolic disorders in Alzheimer disease and vascular dementia: Two roads converged. Arch Neurol 66, 300-305.

[46] Craft S (2006) Insulin resistance syndrome and Alzheimer disease: Pathophysiologic mechanisms and therapeutic implications. Alzheimer Dis Assoc Disord 20, 298-301.

[47] Pappas C, Andel R, Infurna FJ, Seetharaman S (2017) Glycated haemoglobin (HbA1c), diabetes and trajectories of change in episodic memory performance. J Epidemiol Community Health 71, 115-120.

[48] Ravona-Springer R, Moshier E, Schmeidler J, Godbold J, Akrivos J, Rapp M, Grossman HT, Wysocki M, Silverman JM, Haroutunian V, Beeri MS (2012) Changes in glycemic control are associated with changes in cognition in nondiabetic elderly. J Alzheimers Dis 30, 299-309.

[49] Bruehl H, Sweat V, Tirsi A, Shah B, Convit A (2011) Obese adolescents with type 2 diabetes mellitus have 
hippocampal and frontal lobe volume reductions. Neurosci Med 2, 34-42.

[50] Gannon MC, Nuttall FQ (2004) Effect of a high-protein, low-carbohydrate diet on blood glucose control in people with type 2 diabetes. Diabetes 53, 2375-2380.

[51] Skytte MJ, Samkani A, Petersen AD, Thomsen MN, Astrup A, Chabanova E (2019) A carbohydrate-reduced high-protein diet improves $\mathrm{HbA} 1 \mathrm{c}$ and liver fat content in weight stable participants with type 2 diabetes: A randomised controlled trial. Diabetologia 62, 20662078.

[52] Crook TH, Bartus RT, Ferris SH, Whitehouse P, Cohen GD, Gershon S (1986) Age-associated memory impairment: Proposed diagnostic criteria and measures of clinical change - report of a national institute of mental health work group. Dev Neuropsychol 2, 261-276.

[53] Kennedy G, Meyer D, Hardman RJ, MacPherson H, Scholey AB, Pipingas A (2018) Physical fitness and aortic stiffness explain the reduced cognitive performance associated with increasing age in older people. J Alzheimers Dis 63, 1307-1316.

[54] Scholey AB, Camfield DA, Hughes ME, Woods W, K Stough CK, White DJ, Gondalia S V, Frederiksen PD (2013) A randomized controlled trial investigating the neurocognitive effects of Lacprodan ${ }^{\circledR}$ PL-20, a phospholipid-rich milk protein concentrate, in elderly participants with age-associated memory impairment: The Phospholipid Intervention for Cognitive Ageing Rev. Trials 14, 404.

[55] Wechsler D (1987) Wechsler Memory Scale - Revised, The Psychological Corporation, Harcourt Brace and Company, Sidcup, UK.

[56] Crook TH, Feher EP, Larrabee GJ (1992) Assessment of memory complaint in age-associated memory impairment: The MAC-Q. Int Psychogeriatr 4, 165-176.

[57] Folstein MF, Folstein SE, McHugh PR (1975) "Minimental state". A practical method for grading the cognitive state of patients for Athe clinician. J Psychiatr Res 12, 189-198.

[58] Gallagher D, Niles G, Thompson LW (1982) Reliability of the Beck Depression Inventory with older adults. J Consult Clin Psychol 50, 52-153.

[59] Hodge A, Patterson AJ, Brown WJ, Ireland P, Giles G (2000) The Anti Cancer Council of Victoria FFQ: Relative validity of nutrient intakes compared with weighed food records in young to middle-aged women in a study of iron supplementation. Aust N Z J Public Health 24, 576-583.

[60] Giles G, Ireland P (1996) Dietary Questionnaire for Epidemiological Studies.

[61] Bassett JK, English DR, Fahey MT, Forbes AB, Gurrin LC, Simpson JA, Brinkman MT, Giles GG, Hodge AM (2016) Validity and calibration of the FFQ used in the Melbourne Collaborative Cohort Study. Public Health Nutr 19, 2357 2368.

[62] Hebden L, Kostan E, O’Leary F, Hodge A, AllmanFarinelli M (2013) Validity and reproducibility of a food frequency questionnaire as a measure of recent dietary intake in young adults. PLoS One 8, e75156.

[63] Food Standards Australia New Zealand, AUSNUT 2007, https://www.foodstandards.gov.au/science/monitoring nutrients/ausnut/Pages/ausnut2007.aspx

[64] Jacka FN, O'Neil A, Opie RS, Itsiopoulos C, Cotton S, Mohebbi M, Castle D, Dash S, Mihalopoulos C, Chatterton ML, Brazionis L, Dean OM, Hodge AM, Berk M (2017) A randomised, controlled trial of a dietary intervention for adults with major depression (the 'SMILES' trial): Results. BMC Med 15, 23.

[65] Butlin M, Qasem A, Battista F, Bozec E, McEniery CM, Millet-Amaury E, Pucci G, Wilkinson IB, Schillaci G, Boutouyrie P, Avolio AP (2013) Carotid-femoral pulse wave velocity assessment using novel cuff-based techniques: Comparison with tonometric measurement. $J$ Hypertens 31, 2237-2243.

[66] Mattace-Raso FUS, Hofman A, Verwoert GC, Wittemana JCM, Wilkinson I, Cockcroft J, McEniery C, Yasmina, Laurent S, Boutouyrie P, Bozec E, Hansen TW, Torp-Pedersen C, Ibsen H, Jeppesen J, Vermeersch SJ, Rietzschel E, de Buyzere M, Gillebert TC, van Bortel L, Segers P, Vlachopoulos C, Aznaouridis C, Stefanadis C, Benetos A, Labat C, Lacolley P, Stehouwer CDA, Nijpels G, Dekker JM, Ferreira I, Twisk JWR, Czernichow S, Galan P, Hercberg S, Pannier B, Guérin A, London G, Kennedy Cruickshank J, Anderson SG, Paini A, Rosei EA, Muiesan ML, Salvetti M, Filipovsky J, Seidlerova J, Dolejsova M (2010) Determinants of pulse wave velocity in healthy people and in the presence of cardiovascular risk factors: 'Establishing normal and reference values.' Eur Heart J 31, 2338-2350.

[67] Meigs JB, Nathan DM, Cupples LA, Wilson PWF, Singer DE (1996) Tracking of glycated hemoglobin in the original cohort of the Framingham Heart Study. J Clin Epidemiol 49, 411-417.

[68] Geistanger A, Arends S, Berding C, Hoshino T, Jeppsson JO, Little R, Siebelder C, Weykamp C (2008) Statistical methods for monitoring the relationship between the IFCC reference measurement procedure for hemoglobin A1c and the designated comparison methods in the United States, Japan, and Sweden. Clin Chem 54, 13791385.

[69] Weykamp C (2013) HbA1c: A review of analytical and clinical aspects. Ann Lab Med 33, 393-400.

[70] Pipingas A, Harris E, Tournier E, King R, Kras M, Stough CK (2010) Assessing the efficacy of nutraceutical interventions on cognitive functioning in the elderly. Curr Top Nutraceutical Res 8, 79-87.

[71] MacPherson H, Ellis KA, Sali A, Pipingas A (2012) Memory improvements in elderly women following 16 weeks treatment with a combined multivitamin, mineral and herbal supplement A randomized controlled trial. Psychopharmacology (Berl) 220, 351-365.

[72] Harris E, Macpherson H, Vitetta L, Kirk J, Sali A, Pipingas A (2012) Effects of a multivitamin, mineral and herbal supplement on cognition and blood biomarkers in older men: A randomised, placebo-controlled trial. Hum Psychopharmacol Clin Exp 27, 370-377.

[73] Van der Elst W, van Boxtel MPJ, van Breukelen GJP, Jolles J (2005) Rey's verbal learning test: Normative data for 1855 healthy participants aged $24-81$ years and the influence of age, sex, education, and mode of presentation. $J$ Int Neuropsychol Soc 11, 290-302.

[74] Rey A (1958) L'examin clinique en psychologie, Presses Universitaires de France, Paris, France.

[75] Vakhapova V, Cohen T, Richter Y, Herzog Y, Korczyn AD (2010) Phosphatidylserine containing omega $\omega-3$ fatty acids may improve memory abilities in non-demented elderly with memory complaints : A double-blind placebocontrolled trial. Dement Geriatr Cogn Disord 29, 467-474.

[76] Berendsen AM, Kang JH, Feskens EJM, de Groot CPGM, Grodstein F, van de Rest O (2018) Association of longterm adherence to the mind diet with cognitive function 
and cognitive decline in American women. $J$ Nutr Heal Aging 22, 222-229.

[77] Durga J, van Boxtel MP, Schouten EG, Kok FJ, Jolles J, Katan MB, Verhoef P (2007) Effect of 3-year folic acid supplementation on cognitive function in older adults in the FACIT trial: A randomised, double blind, controlled trial. Lancet 369, 208-216.

[78] Voyer D, Voyer SD, Saint-Aubin J (2017) Sex differences in visual-spatial working memory: A meta-analysis. Psychon Bull Rev 24, 307-334.

[79] Pauls F, Petermann F, Lepach AC (2013) Gender differences in episodic memory and visual working memory including the effects of age. Memory 21, 857-874.

[80] Lai JS, Hiles S, Bisquera A, Hure AJ, McEvoy M, Attia J (2014) A systematic review and meta-analysis of dietary patterns and depression in community-dwelling adults. Am J Clin Nutr 99, 181-97.

[81] Walther K, Birdsill AC, Glisky EL, Ryan L (2010) Structural brain differences and cognitive functioning related to body mass index in older females. Hum Brain Mapp 31, 1052-1064.

[82] Gunstad J, Paul RH, Cohen RA, Tate DF, Spitznagel MB, Gordon E (2007) Elevated body mass index is associated with executive dysfunction in otherwise healthy adults. Compr Psychiatry 48, 57-61.

[83] Cansino S, Torres-Trejo F, Estrada-Manilla C, MartínezGalindo JG, Hernández-Ramos E, Ayala-Hernández M, Gómez-Fernández T, Ramírez-González MD, RuizVelasco S (2018) Factors that positively or negatively mediate the effects of age on working memory across the adult life span. GeroScience 40, 293-303.

[84] Erdfelder E, FAul F, Buchner A, Lang AG (2009) Statistical power analyses using $G^{*}$ Power 3.1: Tests for correlation and regression analyses. Behav Res Methods 41, 1149-1160.

[85] Cohen J, Cohen P, West SG, Aiken L (2003) Applied multiple regression/correlation analysis for the behavioral sciences, Lawrence Erlbaum Associates Publishers.

[86] Elias MF, Robbins MA, Budge MM, Abhayaratna WP, Dore GA, Elias PK (2009) Arterial pulse wave velocity and cognition with advancing age. Hypertension 53, 668-673.

[87] Pase MP, Himali JJ, Mitchell GF, Beiser A, Maillard P, Tsao C, Larson MG, Decarli C, Vasan RS, Seshadri S (2016) Association of aortic stiffness with cognition and brain aging in young and middle-aged adults: The Framingham Third Generation Cohort Study. Hypertension 67, 513-519.

[88] Solfrizzi V, Custodero C, Lozupone M, Imbimbo BP, Valiani V, Agosti P, Schilardi A, D'Introno A, La Montagna M, Calvani M, Guerra V, Sardone R, Abbrescia DI, Bellomo A, Greco A, Daniele A, Seripa D, Logroscino G, Sabbá C, Panza F (2017) Relationships of dietary patterns, foods, and micro- and macronutrients with Alzheimer's disease and late-life cognitive disorders: A systematic review. J Alzheimers Dis 59, 815-849.

[89] Crichton GE, Bryan J, Hodgson JM, Murphy KJ (2013) Mediterranean diet adherence and self-reported psychological functioning in an Australian sample. Appetite 70, 53-59.
[90] Qin B, Adair LS, Plassman BL, Batis C, Edwards LJ, Popkin BM, Mendez MA (2015) Dietary patterns and cognitive decline among chinese older adults. Epidemiology 26, 758-768.

[91] Brouwer-Brolsma EM, Benati A, van de Wiel A, van Lee L, de Vries JHM, Feskens EJM, van de Rest O (2018) Higher Mediterranean diet scores are not cross-sectionally associated with better cognitive scores in 20- to 70-yearold Dutch adults: The NQplus study. Nutr Res 59, 80-89.

[92] Shakersain B, Santoni G, Larsson SC, Faxén-Irving G, Fastbom J, Fratiglioni L, Xu W (2016) Prudent diet may attenuate the adverse effects of Western diet on cognitive decline. Alzheimers Dement 12, 100-109.

[93] Agarwal P, Dhana K, Barnes LL, Holland TM, Zhang Y, Evans DA, Morris MC (2021) Unhealthy foods may attenuate the beneficial relation of a Mediterranean diet to cognitive decline. Alzheimers Dement 17, 1157-1165.

[94] Mosconi L, Walters M, Sterling J, Quinn C, McHugh P, Andrews RE, Matthews DC, Ganzer C, Osorio RS, Isaacson RS, De Leon MJ, Convit A (2018) Lifestyle and vascular risk effects on MRI-based biomarkers of Alzheimer's disease: A cross-sectional study of middleaged adults from the broader New York City area. $B M J$ Open 8, e019362.

[95] Bowman GL, Silbert LC, Howieson D, Dodge HH, Traber MG, Frei B, Kaye JA, Shannon J, Quinn JF (2012) Nutrient biomarker patterns, cognitive function, and MRI measures of brain aging. Neurology 78, 241-249.

[96] Pase MP, Himali JJ, Beiser AS, Aparicio HJ, Satizabal CL, Vasan RS, Seshadri S, Jacques PF (2017) Sugar- and artificially sweetened beverages and the risks of incident stroke and dementia. Stroke 48, 1139-1146.

[97] Fava A, Montalcini T, Mazza E, Pujia A, Ferro Y, Bosco D, Rotundo S, Romeo S (2018) Effect of the replacement of dietary vegetable oils with a low dose of extravirgin olive oil in the Mediterranean Diet on cognitive functions in the elderly. $J$ Transl Med 16, 10.

[98] Martínez-Lapiscina EH, Toledo E, Clavero P, Sanjulian B, Sanchez-Tainta A, Corella D, María Lamuela-Raventós R, Martínez JA, Martínez-Gonzalez MÁ (2013) Virgin olive oil-rich mediterranean diet improves cognition: The predimed-navarra randomized, prevention trial. Ann Nutr Metab 62, 36.

[99] Shao A, Drewnowski A, Willcox DC, Krämer L, Lausted C, Eggersdorfer M, Mathers J, Bell JD, Randolph RK, Witkamp R, Griffiths JC (2017) Optimal nutrition and the ever-changing dietary landscape: A conference report. Eur J Nutr 56(Suppl 1), 1-21.

[100] Wengreen HJ, Neilson C, Munger R, Corcoran C (2009) Diet quality is associated with better cognitive test performance among aging men and women. J Nutr 139, 1944-1949.

[101] Reddan JM, White DJ, Macpherson H, Scholey A, Pipingas A (2018) Glycerophospholipid supplementation as a potential intervention for supporting cerebral structure in older adults. Front Aging Neurosci 10, 49. 